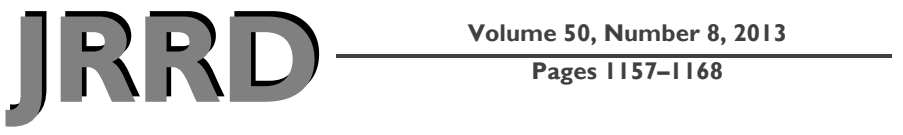

\section{Visual training and emotional state of people with retinitis pigmentosa}

\author{
Helena Chacón-López, PhD; ${ }^{*}$ Francisco J. Pelayo, PhD; ${ }^{2}$ María D. López-Justicia, PhD; ${ }^{1}$ Christian A. Morillas, \\ PhD; ${ }^{2}$ Raquel Ureña, MSc; ${ }^{2}$ Antonio Chacón-Medina, PhD; ${ }^{3}$ Begoña Pino, PhD $^{2}$ \\ ${ }^{1}$ Department of Developmental and Educational Psychology, Faculty of Educational Sciences, ${ }^{2}$ Department of Computer \\ Architecture and Technology, High Technical School of Informatics and Telecommunications, and ${ }^{3}$ Department of Didactics \\ and School Organization, Faculty of Educational Sciences, University of Granada, Spain
}

\begin{abstract}
The purpose of the study was to improve the visual functioning of people with restriction in contrast sensitivity (CS), such as retinitis pigmentosa (RP), by means of a visual training program. Twenty-six volunteers with RP participated, distributed in two groups: 15 who made up the experimental group (who received the training program) and 11 who participated as a control group (without training). Participants were evaluated before beginning training, on completion, and 3 mo following completion for CS with the Pelli-Robson Contrast Sensitivity (P\&R) test, visual functioning with the Visual Function Questionnaire (VFQ), and in emotional state with the Beck Depression Inventory (BDI). The training program is based on software that generates luminous stimuli of varying duration and intensity and registers the stimuli perceived by the subject. The outcomes showed significant differences posttraining in the experimental group in depression $\left(F_{1,14}=5.42 ; p<0.04\right)$, VFQ $(Z=-2.27 ; p<$ $0.02)$, and $\mathrm{P} \& \mathrm{R}$ in the right eye $(Z=-1.99 ; p<0.046)$ and left eye $(Z=-2.30 ; p<0.02)$ but not in binocular $(Z=-0.96$; $p<$ $0.34)$. The outcomes showed that the experimental group made significant progress in all variables and these effects remained after $3 \mathrm{mo}$, which suggests that the program could be a helpful addition to RP rehabilitation and help mitigate the damage.
\end{abstract}

Key words: adults, contrast sensitivity, depression, emotional state, rehabilitation, retinal degenerative diseases, retinitis pigmentosa, visual functioning, visual performance, visual training.

\section{INTRODUCTION}

The degree of autonomy in personal and social performance is assessed by efficiency in carrying out vari- ous daily tasks. In conducting these activities, people with low vision, such as those with retinitis pigmentosa (RP), can have serious difficulties, which may adversely affect their social and personal welfare.

RP belongs to a group of degenerative diseases of the retina characterized by a progressive loss of vision that can lead to blindness. This disorder specifically implies night blindness, peripheral restrictions and/or scotomas (scattered spots in which vision is absent or deficient) in the visual field (VF) [1-3], frequent reduction of visual acuity (VA) [1-4], and alterations in contrast sensitivity (CS) [5-6], showing a significant reduction of CS in a wide range of spatial frequencies. These symptoms affect daily visual functioning, lifestyle, and social development and influence the emotional state [7-8], as well as the visual-perceptual state [9]; therefore, paying attention to these aspects is fundamental in our study.

\footnotetext{
Abbreviations: $\mathrm{BDI}=$ Beck Depression Inventory, $\mathrm{CS}=$ contrast sensitivity, HMD = head-mounted display, MMSE = Mini-Mental State Examination, P\&R = Pelli-Robson Contrast Sensitivity, $\mathrm{RP}=$ retinitis pigmentosa, $\mathrm{SD}=$ standard deviation, $\mathrm{VA}=$ visual acuity, $\mathrm{VF}=$ visual field, $\mathrm{VFQ}=$ Visual Function Questionnaire.

*Address all correspondence to Helena Chacón-López, PhD; Department of Developmental and Educational Psychology, Faculty of Educational Sciences, University of Granada, Campus Universitario de La Cartuja, s/n, 18071-Granada, Spain; +34-958-243-975. Email: helenachacon@ugr.es http://dx.doi.org/10.1682/JRRD.2012.06.0113
} 
Until now, there have been no medical solutions or pharmacological treatments for this pathology or for other degenerative visual problems.

\section{Contrast Sensitivity}

One of the parameters used to assess visual functioning, which significantly influences the performance of daily living activities, is CS [10-12], the ability to discriminate between shades of gray [13]. Assessment of CS is useful for evaluating the effects of some visual deficits because a person may have good VA but diminished CS and therefore may experience some difficulties in certain real-life situations [6-11]. This is the case of some people with RP.

Improvements in CS can be obtained in subjects with normal vision by training them with challenging tasks that involve vision [14]. This training is of great interest to people with RP since the loss of CS is one of the main difficulties faced [15] and significantly affects their ability to carry out daily living tasks [11].

\section{Visual Functioning and Retinitis Pigmentosa}

Various studies have indicated that differences in visual functioning in daily living activities are significant among people with visual impairments such as RP; therefore, their functional performance is considered in their assessment [11,16-18]. It has even been stressed that the outcomes of this assessment are as valuable and complete as the data provided by ophthalmological tests [11-18]. Procedures to evaluate visual functioning include lists or self-report tools used in the tasks in order to record easily observable behaviors. These behaviors make it possible to study visual functioning in daily living activities by measuring visual and psychosocial aspects. Other studies have shown that daily visual functioning can be affected by negative emotional states such as depression [11-18], although depression is also affected by daily living activities.

\section{Emotional State and Retinitis Pigmentosa}

Numerous authors have noted that adults who develop visual restriction have a greater risk of depression [18-21]. Furthermore, depression constitutes a major source of functional disability, and the consequences in adults also affect visual rehabilitation [22-23]. A previous research study showed that emotional adjustment worsens over time [24].

Depression in people with RP is frequent $[7,11,18]$. The prevalence has been estimated at 25.7 percent (while in the general population it amounts to $10 \%$ ). Nemshick et al. showed that the period of greatest crisis or stress occurs during or immediately following diagnosis [25], and López-Justicia et al. recommended evaluating the depression variable just after the diagnosis of the disease and again over time [7].

\section{Visual Stimulation and Retinitis Pigmentosa}

Some years ago, procedures for assessment and for perceptual and visual training began to be applied to adults with visual deficiencies (including RP) in order to improve their visual functioning and performance in certain situations of everyday life [16-17]. These studies concluded that practice and training could improve the functional use of residual vision, although it was also observed that people who were more actively involved in training made better use of their residual vision [16]. Thus, both practice and motivation seem to be decisive factors in improving the use of residual vision.

Visual stimulation and training are highly relevant in interventions with people affected by low vision, even when the level of remaining vision is very low. This type of training has been proven to be effective in enhancing their quality of life regardless of the patient's age [2627]. The aim of visual stimulation and visual training is to train affected people in using their visual functions so that they achieve both a quantitative and a qualitative enhancement in social functioning [26-27]. Likewise, visual stimulation and training allow affected people to use their remaining VA ability [28]; this aspect should not be disregarded, because it has been confirmed that a large number of RP-affected individuals maintain some VA to the end of their lives, even if it is minimal [29]. This fact is undoubtedly valuable for planning education and rehabilitation activities [30].

On the other hand, methods for training the visual system in people with VF deficit have been developed using computer programs to stimulate, through luminous points, the edge of the region of the VF situated between a visually intact area and a damaged area [31], resulting in a significant increase in visual function. For a long time, it was believed that these problems could not be treated since it was thought that vision required a high degree of neuronal organization produced during the early stages of life. Nevertheless, despite this specific period for organization, a considerable degree of plasticity has been documented in the adult visual system damaged by a lesion: a reorganization of the neuron receptive field occurs following lesions 
in the retina or cortex, with cortical neurons with receptive fields associated with the damaged area of the retina acquiring new fields in adjacent areas [32]. Some of the criticisms of these procedures have pointed out that the increase in VF produced could be explained by movement of the eyes toward the affected area in an attempt to compensate for the deficit in VF [33-34].

\section{Purpose of Study}

The final purpose of this study was to improve the CS of people with limited CS, such as those with RP, by means of a visual training program.

Assuming as a starting hypothesis that it is possible to improve the CS of people with difficulties in this function, we have applied a training program based on the stimulation of VF with different levels of contrast and using covert direction of attention. It is known that covert attention, or orientation of the attention toward visual stimuli that appear in areas other than the fixation point, improves the response of the visual system [35]. We also hypothesized that visual training would lead to an improvement both in functional vision in daily living activities (specifically CS) and in emotional state.

\section{METHODS}

\section{Participants}

A meeting was organized for people with RP, members of the RP Association of Andalusia (who participated in research coordinated by two of the authors), to inform them about the objectives of the study and the activities involved. A sample of 26 volunteers with RP was then selected from all those who agreed to participate and who fulfilled the inclusion criteria: having bilateral VF loss ranging between $5^{\circ}$ and $40^{\circ}$ (binocular), having VA ranging between 20/20 (0.0 logMAR unit) and 20/200 (1.0 $\operatorname{logMAR}$ unit) in the better eye, and presenting no cognitive impairment (score greater than 24 measured with Mini-Mental State Examination [MMSE]). These participants were asked to provide an ophthalmological report, including the diagnosis and the degree of VA and VF. Their VA was measured with Snellen acuity charts, and their monocular and binocular kinetic VF was measured with a Goldmann Perimeter (V4, III4, I4, II2). Later, they were randomly assigned (considering VA and VF) into two groups: 15 (13 women and 2 men) who made up the experimental group (who received the training program), and 11 ( 8 women and 3 men) who participated as a control group (without training program). There were no significant differences between the groups in VA (right eye: $\chi^{2}=$ 2.36, $p=0.50$; left eye: $\chi^{2}=6.36, p=0.10$; binocular: $\left.\chi^{2}=6.36, p=0.10\right)$ or in VF $\left(\chi^{2}=11.46, p>0.99\right)$. The participants were evaluated before starting the training period (pre-), on completion (post-) and 3 mo following completion (post $3 \mathrm{mo}$ ). At each evaluation, participants completed the following tests: the Pelli-Robson Contrast Sensitivity (P\&R) test, the Visual Function Questionnaire (VFQ), and the Beck Depression Inventory (BDI). VA was measured only before beginning training and on completion. The participants in the control group were informed that they could undertake the training program in a second phase of the study.

Table 1 shows the demographic characteristics of the participants by groups. Four had associated incipient cataracts, one had mild central macular edema in one eye, another had very incipient macular degeneration in one eye, and three had photopsia (sensation of seeing lights, sparks, or colors). The presence of ring scotomas or temporal islands was not included in the reports. Participants had been diagnosed between 2 and $57 \mathrm{yr}$ before (mean $=14.58$, standard deviation $[\mathrm{SD}]=11.16$ ). None of the participants

Table 1.

Demographic characteristics of participants by group.

\begin{tabular}{lcc}
\hline \multicolumn{1}{c}{ Characteristic } & $\begin{array}{c}\text { Experimental } \\
\text { Group }\end{array}$ & Control Group \\
\hline Age (yr) & $22-57$ & $17-57$ \\
Range & $43.00 \pm 10.55$ & $36.64 \pm 13.06$ \\
Mean \pm SD & & \\
Sex & 13 & 8 \\
$\quad$ Female & 2 & 3 \\
Male & & $0.00-1.00$ \\
VA (logMAR unit) & $0.00-1.00$ & $0.30-1.00$ \\
RE Range & $0.30-1.00$ & \\
LE Range & $5.00-40.00$ & $5.00-40.00$ \\
VF & $14.80 \pm 9.49$ & $17.73 \pm 13.11$ \\
Range & 2 & - \\
Mean \pm SD & 2 & - \\
Associated Visual Pathologies & 1 & - \\
Incipient Cataracts & 1 & \\
Photopsia & & \\
Mild Central Macular Edema & & \\
Mild Macular Degeneration & & \\
\hline LE = left eye, logMAR = logarithm of minimum angle of resolution, RE $=$ \\
right eye, VA = visual acuity, VF = visual field. \\
\hline \hline
\end{tabular}


were receiving any type of treatment for depression at the time of the study. One participant had mild central macular edema in one eye.

\section{Materials}

\section{Contrast Sensitivity}

To evaluate CS, we used the P\&R test. The P\&R test, as indicated by Pelli et al. [36], consists of two printed optotype charts, $97 \times 82 \mathrm{~cm}$, with eight lines each showing a different sequence of letters ( 6 per line). All the letters are the same size and are arranged in groups whose contrast varies from high to low. Each group has three letters of the same contrast level, and the contrast is lower in the group on the right. The test can measure up to 16 different contrast values in steps of $0.15 \mathrm{log}$ units, from 0.0 to 2.25 .

\section{Visual Functioning}

The National Eye Institute VFQ (VFQ-25, version 2000) was used to obtain a measure of the individual visual functioning in everyday life [37]. This instrument is composed of 38 items that provide a general measure of the difficulties associated with vision in daily life in people with chronic eye diseases, as well as 11 subscales that evaluate emotional well-being and social functioning: general health and general vision, near vision, distance vision, driving, peripheral vision, color vision, ocular pain, specific visual limitations (role difficulties), dependency, social functioning, and mental health. The questionnaire measures, therefore, visual and psychosocial aspects that belong to visual functioning in everyday life. The answers to the items range between 1 and 5 points, depending on which best fits the respondent's situation. These scores are converted to a 0 to 100 scale, so higher scores mean better visual functioning. The questionnaire enabled us to obtain scores in each of the subscales (although in the present study we have omitted the results in the driving subscale because only one participant could do it) and an overall score.

We chose this scale because it is much used and cited in recent years and there are studies that underpin its utility in the population with RP [18]. The psychometric properties of the scale are robust (the reliability ranges between 0.71 and 0.85 and it has reliability equal to or greater than 0.70, in all the subscales) [37].

\section{Depression}

We used the BDI to evaluate depression [38]. The BDI is a self-applicable instrument validated for the Spanish population [39] to quantify symptoms of depression in normal and clinical populations. The BDI has an average reliability (alpha coefficient) of 0.86 [40]. The version used in this study was the abbreviated scale of 13 items, and there is a high correlation $(0.96)$ between both forms [38]. In this version, the respondent must choose a sentence from four options, listed in order of severity. Each item is assessed with different options of answers from 0 to 3 , giving a total possible score of 39 points. The following scores were taken into account: 0 to $4=$ absence of depression, 5 to $7=$ mild depression, 8 to $15=$ moderate depression, and $>15=$ serious depression [41].

\section{Training Program}

The instruments for the training program consisted of a personal computer, a head-mounted display (HMD), and software that generates the training patterns and registers the responses of the user during each session. Visual stimuli consisted of bright spots of varying intensity, duration, and position generated within the VF of the HMD, first for each eye in monocular vision and then in binocular vision.

Using an HMD allowed us greater control over the illumination conditions, as well as helping to avoid any possible sources of distraction. The software included in the training program generated the visual stimuli on the HMD and registered the response of the participant when he or she perceived it and pressed a key. The visual field was divided into a regular grid of eight by eight areas or cells arranged into four quadrants of the screen, with the stimuli located at the center of the cells. Stimuli were shown in all the defined positions at three different levels of intensity, $1 / 3,2 / 3$, and 1 , with 1 corresponding to the highest intensity. During each complete training stage (either monocular or binocular), the 64 defined areas were stimulated once with each of the three intensity levels in each position presented randomly (64 stimuli per intensity level).

During the whole training session, a fixation point remained in the center of the screen, where the participants had to direct his or her gaze at all times. Before presenting each new stimulus, the quadrant in which it was due to appear was pointed at by an arrow in the center of the visual field behind the fixation point. The arrow remained in this position for a random variable time 
(400-600 ms) before the stimulus appeared. The stimulus was then displayed for $200 \mathrm{~ms}$. In some randomly selected cases, the stimulus was not provided, with the intention of avoiding any tendency toward false positives. Once the stimulus disappeared, there was a variable period of time during which the participant had to press a computer key to register the event as soon as he or she saw it. The time for registering events was also chosen randomly within a range between 400 to $600 \mathrm{~ms}$.

The use of variable temporal ranges both in the stage prior to the display of the stimulus and in the phase in which, if it is perceived, it is recorded was intended to create a different duration for different stimulation cycles; we hoped that this would avoid participants registering stimuli that they had not seen because they were simply following a repetitive periodic response to the stimuli.

With the information generated in each session, a complete and detailed analysis of the development of each participant can be carried out.

\section{Procedure}

The procedure followed for applying the P\&R test consisted of all the participants in the study reading (in monocular and binocular vision) the letters located on the optotype, beginning with the top row and continuing until two of the three letters in the same group were read incorrectly.

The participants sat in front of the chart at a distance of $1 \mathrm{~m}$ with the center of the chart at eye level, avoiding reflections on the surface of the chart. All participants were assessed at the same location and under identical conditions, maintaining the illumination constant and consistent with that established by the authors. The illumination was measured, following the recommendation of the test instructions, using a Lumix DMC-L1 camera with a Leica D Vario-Elmarit $14-50 \mathrm{~mm} \mathrm{f/2.8-3.5} \mathrm{lens}$ (Panasonic; Kadoma, Japan), adjusted to 100 ASA, so that the illumination of the room corresponded to the combination of $1 / 15 \mathrm{~s}$ and aperture of $\mathrm{f} / 5.6$.

Next, following a break after the CS test, we proceeded to evaluate VFQ (VFQ-25, version 2000) [37] and depression. The evaluation was carried out by the same researcher, administered in the same laboratory with the same luminance levels. Approximately $2 \mathrm{~h}$ were required to conduct all the tests.

The training phase for each participant was planned for a period of $3 \mathrm{mo}$, with daily $15 \mathrm{~min}$ sessions in the participant's home and $1 \mathrm{~d}$ off per week. Each session was divided into three phases: two to train each eye separately and a third for binocular training. The software program and HMD were installed on the laptops of all participants so that they could carry out the training at home, without having to travel. In the beginning of each phase at every training session, the software repeated the instructions through a message displayed on the HMD and a recorded speech. These instructions consisted of keeping their gaze on the central fixation point and pressing the laptop keyboard every time a stimulus was perceived. At the end of the session, when the three phases were completed, a message was displayed showing a measure related to the performance of the session, computed using the number of stimuli at each intensity that the user perceived. For each session, a file was generated containing all the relevant information for a later analysis: perceived stimuli (their intensity and location) and a timestamp to control the training follow-up. We recommended that participants complete the training every day during the same time frame, at a time when they were calm and could concentrate and when other factors would not interfere.

The participants were instructed to keep their eyes on the fixation point and to avoid eye movements during the intervention, although this was not monitored in every training session. However, at the beginning of each of the three stages, participants were reminded of this instruction with a message displayed on the HMD and with a spoken message that they carry out the training task by keeping their eyes on the fixation point.

During the training period, the process was monitored by a telephone call every $15 \mathrm{~d}$, registering the most notable aspects of the participants' experience. No procedures were applied to affect the emotional state.

\section{RESULTS}

\section{Statistical Analyses}

\section{Pretraining Measures}

Since the violation of the homogeneity of variance between the experimental group and control group can lead to biased results in the analyses of unequal sample sizes, the Kolmogorov-Smirnov test was performed in the depression variable in the experimental group $(p>$ $0.90)$ and in the control group $(p>0.66)$. No significant differences were found between the two groups $(F=$ $1.99, p=0.18)$. It was also performed for differences 
between groups in depression $(F=1.99 ; p=0.18)$ and VFQ variables $\left(\chi^{2}=3.08, p>0.99\right)$. The depression scores and VFQ scores at pretest did not differ between the experimental group and control group.

Table 2 shows the mean score and SD of both groups in depression, P\&R test, and VFQ before beginning training, on its completion, and 3 mo following completion. VA only shows two measures, before beginning training and after finishing it.

Table 3 shows the mean score and SD of both groups in VFQ subscales in the three assessments.

\section{Correlation Studies}

Spearman correlation analysis between the two groups showed a negative and significant relationship between levels of depression and VFQ $(\rho=-0.64, p<$
$0.01)$ in both the experimental group $(\rho=-0.73, p<0.01)$ and in the control group $(\rho=-0.84, p<0.001)$. No correlation was found between levels of depression and VA in the right eye $(\rho=-0.25, p<0.26)$, left eye $(\rho=-0.12$, $p<0.59)$, or binocular $(\rho=-0.08, p<0.97)$ or between levels of depression and CS in the right eye $(\rho=-0.18$, $p<0.42)$, left eye $(\rho=-0.39, p<0.09)$, or binocular $(\rho=$ $-0.17, p<0.47)$.

\section{Results of Depression Variable}

Different linear models of repeated measurements $(2 \times$ 2: two groups $\times$ two levels of measurements: pretraining and posttraining) were carried out for the depression variable. The main effect of group $\left(F_{1,24}=0.34, p<0.57\right)$ and the two levels of measurements $\left(F_{1,24}=0.01, p<0.91\right)$ showed

Table 2.

Mean \pm standard deviation scores in depression, visual acuity (VA), Pelli-Robson Contrast Sensitivity (P\&R) test, and Visual Function Questionnaire (VFQ) of two groups.

\begin{tabular}{|c|c|c|c|c|c|c|}
\hline \multirow{2}{*}{ Measure } & \multicolumn{2}{|c|}{ Pre } & \multicolumn{2}{|c|}{ Post } & \multicolumn{2}{|c|}{ Post 3 mo } \\
\hline & EG & $\mathbf{C G}$ & EG & $\mathbf{C G}$ & EG & $\mathbf{C G}$ \\
\hline Depression & $5.08 \pm 4.54$ & $2.56 \pm 2.69$ & $3.66 \pm 3.89$ & $4.11 \pm 5.60$ & $3.25 \pm 4.09$ & $4.66 \pm 4.82$ \\
\hline VA-LE & $0.19 \pm 0.59$ & $0.20 \pm 0.64$ & $0.15 \pm 0.60$ & $0.20 \pm 0.64$ & - & - \\
\hline VA-B & $0.19 \pm 0.59$ & $0.20 \pm 0.64$ & $0.15 \pm 0.60$ & $0.20 \pm 0.64$ & - & - \\
\hline P\&R-RE & $1.45 \pm 0.47$ & $1.53 \pm 0.42$ & $1.55 \pm 0.46$ & $1.53 \pm 0.42$ & $1.58 \pm 0.52$ & $1.53 \pm 0.42$ \\
\hline P\&R-B & $1.69 \pm 0.26$ & $1.63 \pm 0.44$ & $1.73 \pm 0.26$ & $1.63 \pm 0.44$ & $1.74 \pm 0.27$ & $1.63 \pm 0.44$ \\
\hline VFQ & $63.92 \pm 15.64$ & $60.64 \pm 19.33$ & $67.08 \pm 16.01$ & $61.53 \pm 18.78$ & $65.60 \pm 18.11$ & $61.48 \pm 18.99$ \\
\hline
\end{tabular}

$\mathrm{B}=$ binocular, $\mathrm{CG}=$ control group, $\mathrm{EG}=$ experimental group, $\mathrm{LE}=$ left eye, $\mathrm{RE}=$ right eye.

Table 3.

Mean Visual Function Questionnaire subscale scores (mean \pm standard deviation) in two groups.

\begin{tabular}{|c|c|c|c|c|c|c|}
\hline \multirow{2}{*}{ Subscale } & \multicolumn{2}{|c|}{ Pre } & \multicolumn{2}{|c|}{ Post } & \multicolumn{2}{|c|}{ Post 3 mo } \\
\hline & EG & CG & EG & CG & $\mathbf{E G}$ & $\mathbf{C G}$ \\
\hline General Health & $68.66 \pm 13.39$ & $71.36 \pm 22.42$ & $69.83 \pm 15.10$ & $72.72 \pm 20.44$ & $71.83 \pm 16.72$ & $72.00 \pm 20.73$ \\
\hline Ocular Pain & $78.33 \pm 21.37$ & $76.13 \pm 18.07$ & $85.38 \pm 16.63$ & $80.07 \pm 17.38$ & $84.16 \pm 19.17$ & $79.80 \pm 17.54$ \\
\hline Near Activities & $66.10 \pm 23.03$ & $59.84 \pm 28.52$ & $64.44 \pm 23.82$ & $61.66 \pm 28.79$ & $63.83 \pm 25.05$ & $61.49 \pm 28.95$ \\
\hline Distance Activities & $57.77 \pm 19.08$ & $53.37 \pm 22.50$ & $55.55 \pm 16.49$ & $56.16 \pm 22.11$ & $56.10 \pm 15.65$ & $56.43 \pm 22.22$ \\
\hline Mental Health & $67.66 \pm 23.05$ & $60.45 \pm 29.19$ & $73.00 \pm 22.89$ & $65.45 \pm 29.10$ & $70.33 \pm 23.25$ & $65.45 \pm 29.10$ \\
\hline Role Difficulties & $62.50 \pm 19.33$ & $50.00 \pm 19.96$ & $58.75 \pm 20.16$ & $47.45 \pm 14.44$ & $56.25 \pm 21.65$ & $47.45 \pm 14.44$ \\
\hline Dependency & $72.50 \pm 27.01$ & $63.63 \pm 29.02$ & $80.41 \pm 23.12$ & $65.45 \pm 31.74$ & $71.66 \pm 29.77$ & $65.18 \pm 31.75$ \\
\hline Color Vision & $75.00 \pm 25.00$ & $77.27 \pm 26.11$ & $78.33 \pm 20.84$ & $75.00 \pm 27.38$ & $80.00 \pm 27.05$ & $75.00 \pm 27.38$ \\
\hline Peripheral Vision & $43.33 \pm 22.09$ & $36.36 \pm 20.50$ & $45.00 \pm 16.90$ & $36.36 \pm 23.35$ & $43.33 \pm 19.97$ & $36.18 \pm 23.24$ \\
\hline
\end{tabular}


no significant differences, but there was a significant interaction between the two variables $\left(F_{1,24}=6.12, p<0.02\right)$. A new linear model of the effects of the two levels of measurements on the levels of groups showed significant differences in the experimental group $\left(F_{1,14}=5.42, p<0.04\right)$ but not in the control group $\left(F_{1,10}=1.89, p<0.21\right)$. This confirms an improvement in the participants of the experimental group in the depression variable.

In order to know if the improvement was maintained, a new analysis posttraining and post 3 mo (using the $t$-test) was carried out. Since a decrease in depression can be expected as a result of training, we used a one-sided test, that is, halving the $p$-values found in the two-side $t$-test. In the experimental group, no significant differences were found between posttraining and post $3 \mathrm{mo}(t=0.62$, $p=0.27)$, but significant differences were found between pretraining and post 3 mo scores $(t=2.30, p=0.02)$. No significant differences were found in the control group between posttraining and post $3 \mathrm{mo}(t=-1.64, p=0.07)$, but significant differences were found between pretraining and post 3 mo scores $(t=-2.22, p=0.03)$, confirming an increase in the depression variable, contrary to what was observed in the experimental group.

\section{Results in Visual Function Questionnaire Variable}

The Wilcoxon signed-rank test was used to compare the scores of the two groups in VFQ. The results of this test in pretraining and posttraining showed significant differences in the experimental group $(Z=-2.27, p<0.02)$, but not in the control group $(Z=-1.12, p<0.26)$. No significant differences were found in posttraining and post 3 mo measurements in the experimental group $(Z=-1.36$, $p<0.17)$, nor in the control group $(Z=-0.68, p<0.50)$.

\section{Results in Pelli-Robson Contrast Sensory Test Variable}

In the P\&R test, Wilcoxon signed-rank test showed significant differences in pretraining and posttraining scores in the experimental group in the right eye $(Z=-1.99, p<$ $0.046)$ and the left eye $(Z=-2.30, p<0.02)$, but not in binocular $(Z=-0.96, p<0.34)$. No significant differences were found in the control group in the right eye, left eye, and binocular $(Z=1.00, p<0.32)$. In the posttraining and post 3 mo scores, no significant differences were found in the experimental group in the right eye score $(Z=-0.21, p<$ $0.83)$, left eye $(Z=-1.49, p<0.14)$ and binocular $(Z=0.01$, $p>0.99)$, although significant differences were found between pretraining and post 3 mo scores in the right eye $(Z=-2.68, p<0.01)$ and in the left eye $(Z=-2.30$, $p<0.02)$, but not in binocular $(Z=-0.72, p<0.47)$. In the control group, no significant differences were found between posttraining and post 3 mo scores, or between pretraining and post 3 mo scores.

\section{Results in Visual Acuity Variable}

In the VA evaluation posttraining, Wilcoxon signedrank test showed no significant differences in the experimental group score in the right eye $(Z=-0.16, p<0.11)$, left eye $(Z=-0.92, p<0.36)$, and binocular $(Z=-0.18$, $p<0.85)$. No significant differences were found in the control group in the right eye, left eye, or binocular, maintaining the initial mean scores.

\section{Results in Training Program}

To assess the gain score for each trained contrast level $(1 / 3,2 / 3$, and 1$)$, the average number of stimuli perceived in the last seven training sessions as compared to the first seven sessions was calculated over a maximum of 64 shown stimuli, taking into account the stimuli perceived with each eye individually and in binocular. Table 4 shows these numbers and the average gain score at each contrast level, which has been calculated individually for each participant with the following expression: $(b-a) /(64-a)$, where $b$ is the average number of stimuli perceived in the last seven sessions, and $a$ the average of the first seven sessions.

The average gain score achieved by the group was 26 percent for low-contrast stimuli, 20 percent for mediumcontrast, and 6 percent for high-contrast. These results enabled us to confirm that the participants undergoing training improved in the three contrast levels, but especially in the low-contrast stimuli, as can be seen from the percentage values and also from the increase in the average number of perceived stimuli. The average number of completed training sessions was $58.1(74.5 \%)$.

Table 4.

Number of perceived stimuli (average of both eyes and binocular) at beginning and end of training program, and gain score.

\begin{tabular}{lccc}
\hline $\begin{array}{l}\text { Contrast } \\
\text { Level }\end{array}$ & First Week & Last Week & Gain Score \\
\hline $1 / 3$ & 23.87 & 31.76 & 0.26 \\
$2 / 3$ & 33.37 & 37.41 & 0.20 \\
1 & 36.85 & 39.32 & 0.06 \\
\hline \hline
\end{tabular}




\section{DISCUSSION}

The final aim of the present study was to improve the CS of people with restriction in contrast, such as those with RP, through the training of CS. The results obtained confirm an improvement in the participants of the experimental group in CS, depression, and visual functioning, associated with the training. No significant improvement was found in VA.

\section{Contrast Sensitivity and Visual Acuity}

Given the data obtained on CS, we can confirm positive progression for people who carried out the training program. That improvement was maintained 3 mo after the conclusion of the training. There was also an improvement in the three contrast levels, especially in the lowcontrast stimuli. We believe that these results are very interesting because, as has been widely argued, improvements in CS may facilitate the performance of visual processing at different stages of the visual system [13]. It is important to highlight this because the loss of CS is one of the main difficulties faced by affected individuals and seriously affects their daily life [11]. A look at the scores obtained in the P\&R test reveals an improvement in each eye separately and in binocular vision after training (Table 2). However, in the case of binocular vision the improvement is not significant. Perhaps a larger sample or completing a higher number of training sessions would have allowed us to detect improvement in binocular vision. Note that there are no changes between the two evaluations in the control group, with scores remaining at the initial levels.

These findings are partially consistent with findings of Fahle and Poggio [42], who reported improvements in VA and CS after visual training, proving that perceptual training, previously considered not applicable to the treatment of adults, is effective for the treatment of, for instance, amblyopia and presbyopia [13,43-44], although in this study we have found no significant differences in VA. It should be noted that a possible limitation of the study lies in the wide range of VA and VF. Although a smaller range would have been desirable, the groups were, at least, homogeneous as shown by the statistical tests carried out. Also, in accordance with Hahm et al. [18] and Szlyk et al. [11], the assessment of visual functioning was as valuable and complete as the data provided by ophthalmologic tests and the results of VFQ pretreatment showed no significant differences between the two groups.

\section{Emotional State and Visual Functioning}

The results of Spearman correlation analysis highlight that there is a negative and significant correlation between the level of depression and visual functioning, which is in line with the data found in the studies by Hahm et al. [18] and Szlyk et al. [11]. For this reason, it seems reasonable to conclude that an improvement in visual functioning favors the emotional state and quality of life. The results obtained in our study showed an improvement in both variables of those who participated in the training program compared with the control group. It should be noted that the initial level of depression was in the limit range of mild depression and we observed a decrease in the scores obtained after the training and post 3 mo. This result has to be borne in mind when compared with those of the control group, which showed a slight increase (also in post 3 mo evaluation) in an even lower range of mild depression.

In spite of the great variability and heterogeneity between the participants in both groups (as demonstrated by the high SDs) and the slightly higher initial score in VFQ score in the experimental group, an improvement was noted in the experimental group. Certainly, the data from our study do not allow us to confirm emphatically that the improvement was due to participation in the program; however, they seem to confirm that participating in the program benefitted both visual functioning and emotional well-being. This improvement cannot be ascribed to the implementation of any psychological procedure to reduce levels of depression, because no such procedure or treatment was applied. Instead, the improvement could be related to the mutual influence of emotional state and visual functioning, also observed in other studies. For example, Hahm et al. [18] and Szlyk et al. [11] have pointed out the negative influence of the emotional state on visual functioning, which reduces people's visionrelated quality of life, while Grant et al. [22] also stressed that the psychological state may influence vision rehabilitation programs.

Possibly, the opportunity to participate in the experiment and to make improvements in their training sessions (once the training session was completed the participants received an overall evaluation of the use of the session calculated by the number of stimuli perceived at each intensity) had an effect on the improvement of their emotional 
state. In this sense, it must be stressed that all participants were volunteers with a moderate level of involvement, especially those in the experimental group (as evidenced by the regular and normal development of training for $74.5 \%$ training sessions). This may explain the favorable changes found, corroborating the results obtained in previous studies that demonstrate that practice and motivation seem to determine improvement [16]. Possibly, as stated by Herse [45], the simplest intervention may prove highly effective in enhancing quality of life and personal well-being.

\section{Limitations}

Although the results obtained seem encouraging, we are aware that they should be considered with caution because of the small sample size. Additional studies with larger samples will be needed to confirm our findings. Another limitation is the voluntary nature of participation in the study, which may explain, at least in part, the moderate degree of motivation.

Although the participants were instructed to keep their eyes on the fixation point and to avoid eye movements during the intervention, it would be desirable to control this factor. This task would be easier to carry out with the help of an eye-tracker if the training were carried out with a conventional monitor instead of the HMD we used. Nevertheless, we consider that the use of the HMD not only allows training to be less affected by the conditions of ambient illumination, but also decreases the effect of possible distractions that divert the attention, and therefore less effort is required to maintain the fixation point during the training session.

\section{CONCLUSIONS}

The results obtained seem encouraging since they highlight an improvement in CS, visual functioning, and emotional state of people with a degenerative retinal disease for which there is currently no treatment and the development and prognosis are not favorable. Although we did not find studies that analyze training to improve $\mathrm{CS}$ in people with RP that would have enabled us to compare our results, we believe that initiatives such as this can contribute to better functional and emotional wellbeing of this population.

For this reason, we think that the training program applied is a helpful addition to RP rehabilitation and that the findings of our study have important implications in planning interventions with people with RP. We should not forget the repercussions that visual impairments such as RP have on the emotional state and daily activities of those who are affected $[7,11,18]$. Hence, training to improve visual functioning may favor their personal, social, and professional integration.

\section{ACKNOWLEDGMENTS}

\section{Author Contributions:}

Study concept and design: H. Chacón-López, F. J. Pelayo, M. D. López-Justicia, C. A. Morillas, R. Ureña, A. Chacón-Medina, B. Pino. Acquisition of data: H. Chacón-López, F. J. Pelayo, M. D. LópezJusticia, C. A. Morillas, R. Ureña, A. Chacón-Medina, B. Pino. Analysis and interpretation of data: H. Chacón-López, F. J. Pelayo, M. D. López-Justicia, C. A. Morillas, R. Ureña, A. Chacón-Medina, B. Pino.

Statistical analysis: H. Chacón-López, F. J. Pelayo, M. D. LópezJusticia, C. A. Morillas, R. Ureña, A. Chacón-Medina, B. Pino. Critical revision of manuscript for important intellectual content: H. Chacón-López, F. J. Pelayo, M. D. López-Justicia, C. A. Morillas, R. Ureña, A. Chacón-Medina, B. Pino.

Financial Disclosures: The authors have declared that no competing interests exist.

Funding/Support: This material was based on work partially supported by the Cátedra Bidons Egara, the Spanish MICINN research project RECVIS (Ref. TIN2008-06893-C03-02), the project GENIL-PYR2010-19 funded by CEI BioTIC GENIL CEB09-0010, and the Junta de Andalucía project P06-TIC02007.

Additional Contributions: The authors wish to express their gratitude to Dr. Joaquin López (from Bidons Egara, S.L.) and Dr. Eduardo Fernández (from the Miguel-Hernández University) for their support and interest in this research; to Dr. José R. Jiménez from the Department of Optics (University of Granada); and to Bridgit McQue for translating parts of the original manuscript into English.

Institutional Review: This research study was approved by the Institutional Review Board of the University of Granada (Spain) in 2009. Informed consent was obtained from all participants.

Participant Follow-Up: The authors plan to inform participants of the publication of this study.

\section{REFERENCES}

1. Alexander KR, Barnes CS, Fishman GA. Deficits in temporal integration for contrast processing in retinitis pigmentosa. Invest Ophthalmol Vis Sci. 2003;44(7):3163-69.

[PMID:12824267]

http://dx.doi.org/10.1167/iovs.02-0812

2. Alexander KR, Rajagopalan AS, Seiple W, Zemon VM, Fishman GA. Contrast response properties of magnocellular and parvocellular pathways in retinitis pigmentosa assessed by the visual evoked potential. Invest Ophthalmol 
Vis Sci. 2005;46(8):2967-73. [PMID:16043873]

http://dx.doi.org/10.1167/iovs.05-0231

3. Geruschat DR, Turano KA. Connecting research on retinitis pigmentosa to the practice of orientation and mobility. J Vis Impair Blind. 2002;96(2):69-85.

4. Madreperla SA, Palmer RW, Massof RW, Finkelstein D. Visual acuity loss in retinitis pigmentosa. Relationship to visual field loss. Arch Ophthalmol. 1990;108(3):358-61. [PMID:2310334]

http://dx.doi.org/10.1001/archopht.1990.01070050056030

5. Akeo K, Hiida Y, Saga M, Inoue R, Oguchi Y. Correlation between contrast sensitivity and visual acuity in retinitis pigmentosa patients. Ophthalmologica. 2002;216(3):185-91. [PMID:12065855] http://dx.doi.org/10.1159/000059627

6. Hyvärinen L, Rovamo J, Laurinen P, Peltomaa A. Contrast sensitivity function in evaluation of visual impairment due to retinitis pigmentosa. Acta Ophthalmol (Copenh). 1981; 59(5):763-73. [PMID:7315229]

7. López-Justicia MD, Polo Sánchez T, Fernández Jiménez C, Díaz Batanero C, Chacón-López H, Chacón Medina A. Depresión y ansiedad en personas con retinosis pigmentaria, sus familiares y un grupo externo. Universitas Psychologica. 2011;10(2):467-76. Spanish.

8. Parmeggiani F, Sato G, De Nadai K, Romano MR, Binotto A, Costagliola C. Clinical and rehabilitative management of retinitis pigmentosa: Up-to-date. Curr Genomics. 2011; 12(4):250-59. [PMID:22131870] http://dx.doi.org/10.2174/138920211795860125

9. Chacón-López H. Dificultades perceptivo-visuales y funcionalidad visual de adolescentes y jóvenes con degeneración retiniana. Int J Develop Education Psychol. 2011; 1(2):145-54. Spanish.

10. Haymes S, Guest D, Heyes A, Johnston A. Mobility of people with retinitis pigmentosa as a function of vision and psychological variables. Optom Vis Sci. 1996;73(10):621-37. [PMID:8916133] http://dx.doi.org/10.1097/00006324-199610000-00001

11. Szlyk JP, Seiple W, Fishman GA, Alexander KR, Grover S, Mahler CL. Perceived and actual performance of daily tasks: Relationship to visual function tests in individuals with retinitis pigmentosa. Ophthalmology. 2001;108(1): 65-75. [PMID:11150266]

http://dx.doi.org/10.1016/S0161-6420(00)00413-9

12. Turano KA, Geruschat DR, Stahl JW, Massof RW. Perceived visual ability for independent mobility in persons with retinitis pigmentosa. Invest Ophthalmol Vis Sci. 1999; 40(5):865-77. [PMID:10102283]

13. Polat U. Making perceptual learning practical to improve visual functions. Vision Res. 2009;49(21):2566-73. http://dx.doi.org/10.1016/j.visres.2009.06.005 [PMID:19520103]
14. Li R, Polat U, Makous W, Bavelier D. Enhancing the contrast sensitivity function through action video game training. Nat Neurosci. 2009;12(5):549-51. [PMID:19330003] http://dx.doi.org/10.1038/nn.2296

15. Spellman DC, Alexander KR, Fishman GA, Derlacki DJ. Letter contrast sensitivity in retinitis pigmentosa patients assessed by Regan charts. Retina. 1989;9(4):287-91. [PMID:2629044] http://dx.doi.org/10.1097/00006982-198909040-00009

16. Conrod BE, Bross M, White CW. Active and passive perceptual learning in the visually impaired. J Vis Impair Blind. 1986;80(1):528-31.

17. Trudeau M, Overbury O, Conrod B. Perceptual training and figure-ground performance in low vision. J Vis Impair Blind. 1990;84(5):204-6.

18. Hahm BJ, Shin YW, Shim EJ, Jeon HJ, Seo JM, Chung H, Yu HG. Depression and the vision-related quality of life in patients with retinitis pigmentosa. Br J Ophthalmol. 2008; 92(5):650-54. [PMID:18356260] http://dx.doi.org/10.1136/bjo.2007.127092

19. Augustin A, Sahel JA, Bandello F, Dardennes R, Maurel F, Negrini C, Hieke K, Berdeaux G. Anxiety and depression prevalence rates in age-related macular degeneration. Invest Ophthalmol Vis Sci. 2007;48(4):1498-1503. [PMID:17389477] http://dx.doi.org/10.1167/iovs.06-0761

20. Horowitz A, Reinhardt JP, Kennedy GJ. Major and subthreshold depression among older adults seeking vision rehabilitation services. Am J Geriatr Psychiatry. 2005; 13(3):180-87. [PMID:15728748] http://dx.doi.org/10.1176/appi.ajgp.13.3.180

21. Wahl H-W, Becker S, Burmedi D, Schilling O. The role of primary and secondary control in adaptation to age-related vision loss: A study of older adults with macular degeneration. Psychol Aging. 2004;19(1):235-39. [PMID:15065949] http://dx.doi.org/10.1037/0882-7974.19.1.235

22. Grant P, Seiple W, Szlyk JP. Effect of depression on actual and perceived effects of reading rehabilitation for people with central vision loss. J Rehabil Res Dev. 2011;48(9): 1101-8. [PMID:22234714] http://dx.doi.org/10.1682/JRRD.2010.05.0080

23. Horowitz A, Reinhardt JP. Adequacy of the mental health system in meeting the needs of adults who are visually impaired. J Vis Impair Blind. 2006;100:871-74.

24. Heyl V, Wahl HW. Psychosocial adaptation to age-related vision loss: A six-year perspective. J Vis Impair Blind. 2001;95(12):739-48.

25. Nemshick LA, McCay V, Ludman F. The impact of retinitis pigmentosa on young adults: Psychological, educational, vocational and social considerations. J Vis Impair Blind. 1986;80(7):859-62.

26. Nguyen NX, Weismann M, Trauzettel-Klosinski S. [Spectrum of ophthalmologic and social rehabilitation at the 
Tübinger Low-Vision Clinic : A retrospective analysis for 1999-2005]. Ophthalmologe. 2008;105(6):563-69. German. [PMID:18299841]

http://dx.doi.org/10.1007/s00347-007-1651-5

27. Burstedt MS, Mönestam E. Self-reported quality of life in patients with retinitis pigmentosa and maculopathy of Bothnia type. Clin Ophthalmol. 2010;4(24):147-54.

[PMID:20390035]

http://dx.doi.org/10.2147/OPTH.S8713

28. Laderman DJ, Szlyk JP, Kelsch R, Seiple W. A curriculum for training patients with peripheral visual field loss to use bioptic amorphic lenses. J Rehabil Res Dev. 2000;37(5): 607-19. [PMID:11322159]

29. Grover S, Fishman GA, Anderson RJ, Tozatti MS, Heckenlively JR, Weleber RG, Edwards AO, Brown J Jr. Visual acuity impairment in patients with retinitis pigmentosa at age 45 years or older. Ophthalmology. 1999;106(9):1780-85. [PMID:10485550] http://dx.doi.org/10.1016/S0161-6420(99)90342-1

30. Laitinen A, Sainio P, Koskinen S, Rudanko S-L, Laatikainen L, Aromaa A. The association between visual acuity and functional limitations: Findings from a nationally representative population survey. Ophthalmic Epidemiol. 2007;14(6):333-42. [PMID:18161606] http://dx.doi.org/10.1080/01658100701473713

31. Kasten E, Wüst S, Behrens-Baumann W, Sabel BA. Computer-based training for the treatment of partial blindness. Nat Med. 1998;4(9):1083-87. [PMID:9734406] http://dx.doi.org/10.1038/2079

32. Kaas JH, Krubitzer LA, Chino YM, Langston AL, Polley $\mathrm{EH}$, Blair N. Reorganization of retinotopic cortical maps in adult mammals after lesions of the retina. Science. 1990;248(4952):229-31. [PMID:2326637] http://dx.doi.org/10.1126/science. 2326637

33. Horton JC. Disappointing results from Nova Vision's visual restoration therapy. Br J Ophthalmol. 2005;89(1):1-2.

[PMID:15615733] http://dx.doi.org/10.1136/bjo.2004.058214

34. Plant GT. A work out for hemianopia. Br J Ophthalmol. 2005;89(1):2. [PMID:15615734] http://dx.doi.org/10.1136/bjo.2004.053173

35. Posner MI. Orienting of attention. Q J Exp Psychol. 1980; 32(1):3-25. [PMID:7367577]

http://dx.doi.org/10.1080/00335558008248231

36. Pelli DG, Robson JG, Wilkins AJ. The design of a new letter chart for measuring contrast sensitivity. Clin Vis Sci. 1988;2(3):187-99.

37. Mangione CM, Lee PP, Gutierrez PR, Spritzer K, Berry S, Hays RD; National Eye Institute Visual Function Questionnaire Field Test Investigators. Development of the 25-item National Eye Institute Visual Function Questionnaire. Arch
Ophthalmol. 2001;119(7):1050-58. [PMID:11448327]

http://dx.doi.org/10.1001/archopht.119.7.1050

38. Beck AT, Rush AJ, Shaw BF, Emery G. Cognitive therapy of depression. New York (NY): Guilford Press; 1987.

39. Vázquez C, Sanz J. Fiabilidad y valores normativos de la versión española del Inventario para la Depresión de Beck de 1978. Clin Salud. 1997;8(3):403-22. Spanish.

40. Beck AT, Steer RA, Carbin MG. Psychometric properties of the Beck Depression Inventory: Twenty-five years of evaluation. Clin Psychol Rev. 1988;8(1):77-100. http://dx.doi.org/10.1016/0272-7358(88)90050-5

41. Joffre-Velázquez VM, Martínez-Perales G, García-Maldonado G, Sánchez-Gutiérrez L. Depresión en estudiantes de medicina. Resultados de la aplicación del inventario de depresión de Beck en su versión de 13 ítems. Alcmeon Revista Argentina de Clínica Neuropsiquiátrica. 2007;14(1):86-93. Spanish.

42. Fahle M, Poggio T. Perceptual learning. Cambridge (MA): MIT Press; 2002.

43. Levi DM, Li RW. Perceptual learning as a potential treatment for amblyopia: A mini-review. Vision Res. 2009; 49(21):2535-49. [PMID:19250947] http://dx.doi.org/10.1016/j.visres.2009.02.010

44. Zhou Y, Huang C, Xu P, Tao L, Qiu Z, Li X, Lu ZL. Perceptual learning improves contrast sensitivity and visual acuity in adults with anisometropic amblyopia. Vision Res. 2006;46(5):739-50. [PMID:16153674] http://dx.doi.org/10.1016/j.visres.2005.07.031

45. Herse P. Retinitis pigmentosa: Visual function and multidisciplinary management. Clin Exp Optom. 2005;88(5):335-50. [PMID:16255692] http://dx.doi.org/10.1111/j.1444-0938.2005.tb06717.x

Submitted for publication June 15, 2012. Accepted in revised form February 11, 2013.

This article and any supplementary material should be cited as follows:

Chacón-López H, Pelayo FJ, López-Justicia MD, Morillas CA, Ureña R, Chacón-Medina A, Pino B. Visual training and emotional state of people with retinitis pigmentosa. J Rehabil Res Dev. 2013;50(8):1157-68. http://dx.doi.org/10.1682/JRRD.2012.06.0113

ResearcherID/ORCID: Helena Chacón-López, PhD: L3677-2013; Francisco J. Pelayo, PhD: E-2428-2012

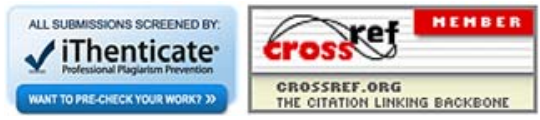


